\title{
BMJ Open Population-based rapid assessment of avoidable blindness survey in Sohag governorate in Egypt
}

\author{
Heba AISawahli (D , ${ }^{1}$ Ian McCormick, ${ }^{2}$ Caleb D Mpyet, ${ }^{3}$ Gamal Ezzelarab, \\ Mohammad Shalaby ${ }^{1}$
}

To cite: AlSawahli $\mathrm{H}$, McCormick I, Mpyet CD, et al. Population-based rapid assessment of avoidable blindness survey in Sohag governorate in Egypt. BMJ Open 2020;10:e036337. doi:10.1136/ bmjopen-2019-036337

- Prepublication history for this paper is available online. To view these files, please visit the journal online (http://dx.doi. org/10.1136/bmjopen-2019036337).

Received 12 December 2019 Revised 20 August 2020 Accepted 04 September 2020

Check for updates

(C) Author(s) (or their employer(s)) 2020. Re-use permitted under CC BY-NC. No commercial re-use. See rights and permissions. Published by BMJ.

${ }^{1}$ Magrabi Foundation, Cairo,

Egypt

'London School of Hygiene and Tropical Medicine International Centre for Eye Health, London, UK

${ }^{3}$ Ophthalmology, Jos University Teaching Hospital, Jos, Nigeria

Correspondence to

Dr Heba AISawahli;

halsawahli@aucegypt.edu

\section{ABSTRACT}

Objectives To determine the prevalence and causes of blindness and vision impairment, and the coverage and quality of cataract surgical services, among population aged 50 years and older in Sohag governorate in Egypt. Design A population-based cross-sectional survey using two-stage cluster random sampling following the rapid assessment of avoidable blindness methodology.

Setting A community-based survey conducted by six teams of ophthalmologists, assistants and local guides. Enrolment and examination were door-to-door in selected clusters.

Participants Using 2016 census data, 68 population units were randomly selected as clusters (of 60 people) with probability proportionate to population size. Anyone aged 50 years and older, residing in a non-institutional setting in a cluster for at least 6 months, was eligible to participate.

Primary and secondary outcome measures The prevalence and causes of blindness and vision impairment Secondary outcomes were CSC and effectiveness and participant-reported barriers to cataract surgery.

Results of 4078 participants enrolled, 4033 (98.9\%) were examined. The age-adjusted and sex-adjusted prevalence of blindness, severe vision impairment and moderate vision impairment were $5.9 \%$ (95\% $\mathrm{Cl} 4.8 \%$ to $6.9 \%$ ), $4.7 \%(95 \% \mathrm{Cl} 3.8 \%$ to $5.7 \%)$ and $18.9 \%(95 \% \mathrm{Cl} 16.8 \%$ to $21.0 \%$ ), respectively. Cataract caused most of blindness (41.6\%), followed by non-trachomatous corneal opacity $(15.7 \%)$ and posterior segment diseases (14.5\%). Cataract surgical coverage (CSC) for persons for visual acuity $<3 / 60$ was $86.8 \%$, the proportion of cataract surgeries with poor visual outcome was $29.5 \%$ and effective CSC (eCSC) was $44.9 \%$. eCSC was lower in women than men. The most frequently reported barrier to surgery was cost (51.5\%). Conclusions The prevalence of blindness in Sohag governorate is higher than districts in other middle-income countries in the region. CSC was high; however, women suffer worse quality-corrected CSC than men. The quality of cataract surgery needs to be addressed, while health system strengthening across government and private settings could alleviate financial barriers.

\section{INTRODUCTION}

In 2018, over 23 million people had vision impaired in the Eastern Mediterranean Region (EMR), of whom 5 million were blind. ${ }^{1}$ Egypt is the most populous country

\section{Strengths and limitations of this study}

- Addresses an overlooked area of research about the epidemiology of blindness in Egypt.

- Standardised cluster random sampling methodology and high response rate provides a representative sample of the population of interest.

- Analysis includes population-reported barriers to cataract surgery and insight on the coverage and quality of cataract services provided in the district.

- The rapid survey methodology may have underestimated the contribution of posterior segment conditions to the burden of vision impairment in the governorate.

- The estimate of uncorrected presbyopia in the sample was based on an assumption that all participants were presbyopic and as such may overestimate the burden of this condition.

in the Middle East with more than 98 million residents. $^{2}$ It is classified as a low-middle income country (LMIC), with a gross domestic product per capita of $\$ 2549$ in 2018. The government allocated $4.2 \%$ of its total expenditure to health in 2016, while out of pocket payments constituted $62 \%$ of all health expenditure. ${ }^{3}$ Sohag governorate lies in the centre of Upper Egypt, the region with the highest levels of poverty in the country. ${ }^{4}$

There are four government hospitals (including one teaching hospital) and many private centres that provide eye care services to approximately five million citizens. ${ }^{5}$ Across these facilities, 81 ophthalmologists carried out 5344 cataract operations-mainly phacoemulsification-in 2014, corresponding to a cataract surgical rate of 1161 per million population compared with 3674 per million population nationally. ${ }^{6}$ Phacoemulsification is a standard practice in private settings, while government hospitals use extracapsular cataract extraction (ECCE) with intraocular lens implantation, due to cost considerations. Small incision cataract surgery is not known to be performed in either setting. ${ }^{6}$ 
Since the 1960 s, there have been very few populationbased, representative surveys of vision impairment in Egypt. ${ }^{7}$ A survey of the population 50 years and older in Menofiya governorate found a prevalence of blindness of $7.9 \% .{ }^{89}$ In 2010, the Ministry of Health and Population (MOHP) carried out surveys of the population 50 years and older in five governorates; however, data were not published. There are discrepancies between national and international vision impairment (VI) data. In 2017, the Central Agency for Public Mobilization and Statistics estimated the all-age prevalence of blindness to be $0.57 \%,{ }^{5}$ while the International Agency for Blindness Prevention estimated it to be $0.96 \%$ for $2015 .^{10}$ The reason for this inconsistency is unclear.

Over the years, gender inequality has been a key finding of blindness and eye health studies in Egypt, ${ }^{7112}$ all found approximately twice as many blind women as blind men in their samples. Egypt lacks a national plan for eye care. In the era of universal health coverage, it is important that eye health planners develop plans to achieve universal eye health-delivering equitable, highquality services and improve quality of life for everyone affected by vision loss.

The objectives of this study were to determine the prevalence and causes of blindness and vision impairment in the population 50 years and older in Sohag governorate, and to report the coverage and quality of cataract surgical services, barriers to cataract surgery, as well as the prevalence of diabetes and diabetic retinopathy. The MOHP will use the data to develop a community-based eye care plan.

\section{METHODS}

A population-based, cross-sectional survey was conducted following the standardised rapid assessment of avoidable blindness (RAAB) methodology, with the addition of the diabetic retinopathy module. ${ }^{13}$ Results of the diabetic retinopathy component will be prepared for publication separately.

\section{Sampling}

The 2016 national census for Sohag governorate showed the population 50 years and older was $627510 .{ }^{5}$ The sample size, calculated using RAAB6 software, was 4080 individuals, based on an expected prevalence of diabetic retinopathy of $4.25 \%$ ( $25 \%$ of the prevalence of diabetes in adults in Egypt, ${ }^{14}$ with a precision of $20 \%$ of the expected prevalence, at $95 \%$ confidence level, non-compliance rate of $15 \%$ and a design effect of 1.6 to compensate for clustering. The prevalence of diabetic retinopathy was used instead of blindness as it was expected to be the lower of the two values.

The sampling frame consisted of 288 urban and rural population units, corresponding to $12 \mathrm{Marakez}$ (districts), based on 2016 census enumeration areas. From this, 68 clusters were selected with probability proportionate to population size. Cluster selection was carried out using the RAAB6 software. Individuals within a population unit were selected through compact segment sampling. Each population unit was divided into equal segments estimated to contain at least 60 people 50 years and older. For large population units, this was done with a grid square overlaid on a Google Maps map of the area. Local community leaders contributed to ensure all segments represented inhabited areas only and one segment was randomly selected for the survey. There was little variation in the arrangement of households between areas defined as urban or rural and most housing was single story. Households in a randomly selected segment were included in the survey until 60 people aged 50 years and older were enrolled. The study used a cluster size of 60 instead of 50 as this was a 'RAAB + Diabetic Retinopathy' survey. In each selected segment, people 50 years and older, residing in non-institutional households for 6 months or more over the past year, were eligible to participate.

\section{Survey teams}

There were six survey teams, each consisting of an ophthalmologist, ophthalmology assistant and local community worker. The six ophthalmologists were masters degree qualified, government employees from Cairo (four), Hurghada and Sohag (one each); all were part of the Magrabi Foundation outreach team. Teams were trained by a certified RAAB trainer and passed an interobserver variation test with a kappa score of at least 0.6 prior to the fieldwork.

\section{Examination protocol}

Presenting visual acuity (PVA) for right and left eyes was measured in ambient illumination, with a $6 / 60$ tumbling E optotype at $6 \mathrm{~m}, 3 \mathrm{~m}$ or $1 \mathrm{~m}$, and $6 / 18$ and $6 / 12$ tumbling E optotypes at $6 \mathrm{~m}$. Pinhole VA was measured where presenting VA was $<6 / 12$ in any eye. All participants had a lens examination by an ophthalmologist using direct ophthalmoscope. Fundus examination using a direct and indirect ophthalmoscope was undertaken by an ophthalmologist to determine the cause of presenting VA $<6 / 12$ as required. Dilated fundus examination, using two drops of tropicamide $0.5 \%$, was carried out where the cause of vision impairment was not uncorrected refractive error, or an obvious corneal or lens opacity (or in line with the RAAB diabetic retinopathy module protocol). Glaucoma was considered the cause of vision impairment or blindness based on only obvious pathological signs (digital palpation, an afferent pupil defect, corneal oedema, a vertical cup-disc ratio of 0.8 or greater) in the absence of intraocular pressure or visual field examination, or where an existing diagnosis of glaucoma was known. Details of the diabetic retinopathy examination protocol undertaken will be reported in detail elsewhere.

WHO definitions of vision impairment and blindness, based on presenting VA in the better eye, were used. Blindness is VA less than $3 / 60$, severe vision impairment (SVI) is VA $3 / 60$ or better and less than $6 / 60$, moderate 
vision impairment (MVI) is VA 6/60 or better and less than $6 / 18$ and early vision impairment (EVI) is VA 6/18 or better and less than $6 / 12$.

Cataract surgical coverage (CSC) is an indicator of to what extent a population's need for cataract surgery has been met. It is the number of people with operated cataract as a proportion of those with operated and operable cataract, for a given level of cataract vision impairment. Effective CSC (eCSC) reports the same proportion; however, it only includes the number of people with operated cataract that have achieved a good visual outcome (ie, can see $6 / 18$ or better) in the numerator. As such, it is a measure of cataract surgical quality in addition to CSC..$^{15}$

Refractive error includes people who presented with distance spectacles plus those whose VA improved from less than 6/12 presenting VA to 6/12 with pinhole. Uncorrected refractive error is the latter group only. Uncorrected presbyopia is defined as all examined people (aged 50 years and older) reporting not having near vision correction. Near VA is not measured in RAAB surveys.

\section{Data collection and statistical analysis}

Field work was completed over 23 days in February 2019. Two teams attended one cluster per day, examining 30 participants each.

Data were collected door-to-door following the standardised RAAB6 two-page survey form and crosschecked daily to identify missing data and correct errors. Survey teams revisited enrolled participants who were not available at the first visit. Two data entry clerks used the RAAB6 software for consistency checks during data entry. Standardised survey reports were generated by RAAB6 software, which accounts for the clustered survey design. Adjusted prevalence estimates were weighted to age and sex disaggregated population data from the 2016 census. A two-sample test of proportions was used in STATA V.16 software to compare the age-adjusted and sex-adjusted prevalences of blindness and vision impairment in men and women. This was a post hoc analysis, using data modified from RAAB's standardised reporting output.

\section{Participants and public involvement in the research}

We did not directly include participants in the design of the research; however, policy makers in the MOHP and local community leaders were consulted about the survey design, questionnaire and approaches to facilitate the implementation of the study. In partnership with the MOHP, we will disseminate a plain language summary of the findings to the public.

\section{RESULTS}

\section{Age and gender distribution}

Among the 4078 people aged 50 years and older enrolled, 13 were unavailable for examination $(0.3 \%), 18$ refused to be examined $(0.4 \%)$ and 14 were not able to communicate $(0.4 \%)$. Accordingly, a total of 4033 participants aged $50+$ were examined, a response rate of $98.9 \%$. The proportion of men in the sample was higher than the population $(59.2 \%$ and $52.1 \%$, respectively); there was a statistically significant difference in the proportions of the male and female population included in the sample $(0.73 \%$ vs $0.55 \%$ [p $<0.001$; two-sample test of proportions]). The youngest age group (50-59) was underrepresented in the sample in contrast to the three older age groups. The difference between the sample population and the study area is presented in table 1 .

\section{Blindness and vision impairment by gender}

The age-adjusted and sex-adjusted prevalence of blindness, SVI and MVI were $5.9 \%$ (95\% CI $4.8 \%$ to $6.9 \%$ ), $4.7 \%(95 \%$ CI $3.8 \%$ to $5.7 \%$ ) and $18.9 \%$ (95\% CI $16.8 \%$ to $21.0 \%$ ), respectively. There was only weak evidence of a statistically significant difference between women and men for blindness $(\mathrm{p}=0.046)$, but strong evidence for the differences between women and men for SVI and MVI ( $p<0.001$ for both). The prevalence of early VI was $17.8 \%$ (95\% CI $16.0 \%$ to $19.5 \%$ ) with no evidence of a difference between sexes $(\mathrm{p}=0.151)$. (table 2$)$.

\section{Causes of blindness and VI}

Cataract was the main cause of blindness (41.2\%) followed by non-trachomatous corneal opacity (15.7\%), and posterior segment diseases $(14.5 \%)$. Glaucoma was responsible for $8.2 \%$ of blindness, while cataract surgical complications were responsible for $7.8 \%$ of blindness

Table 1 Age and sex distribution of survey participants compared with the 2016 census data for Sohag governorate

\begin{tabular}{|c|c|c|c|c|c|c|c|c|c|c|c|c|}
\hline & \multicolumn{4}{|l|}{ Men } & \multicolumn{4}{|c|}{ Women } & \multicolumn{4}{|l|}{ Total } \\
\hline & \multicolumn{2}{|c|}{ Sample } & \multicolumn{2}{|c|}{ Governorate } & \multicolumn{2}{|c|}{ Sample } & \multicolumn{2}{|c|}{ Governorate } & \multicolumn{2}{|c|}{ Sample } & \multicolumn{2}{|c|}{ Governorate } \\
\hline & $\mathbf{n}$ & $\%$ & $\mathrm{n}$ & $\%$ & $\mathbf{n}$ & $\%$ & $\mathbf{n}$ & $\%$ & $\mathbf{n}$ & $\%$ & $\mathbf{n}$ & $\%$ \\
\hline $60-69$ & 846 & 35.4 & 103632 & 31.7 & 568 & 34.5 & 90387 & 30.1 & 1414 & 35.1 & 194019 & 30.9 \\
\hline $70-79$ & 411 & 17.2 & 39858 & 12.2 & 261 & 15.9 & 37423 & 12.5 & 672 & 16.7 & 77281 & 12.3 \\
\hline Total & 2389 & 100.0 & 326966 & 100.0 & 1644 & 100.0 & 300544 & 100.0 & 4033 & 100.0 & 627510 & 100.0 \\
\hline
\end{tabular}


Table 2 Age-adjusted and sex-adjusted prevalence of bilateral blindness, SVI, MVI and EVI, and the projected number of people aged 50 years and older affected in Sohag governorate

\begin{tabular}{|c|c|c|c|c|c|c|c|}
\hline & \multicolumn{2}{|l|}{ Men } & \multicolumn{2}{|l|}{ Women } & \multirow[b]{2}{*}{ P value* } & \multicolumn{2}{|l|}{ Total } \\
\hline & $\begin{array}{l}\text { Projected } \\
\text { number of } \\
\text { people aged } \\
50 \text { years and } \\
\text { older }\end{array}$ & $\%(95 \% \mathrm{Cl})$ & $\begin{array}{l}\text { Projected } \\
\text { number of } \\
\text { people aged } \\
50 \text { years and } \\
\text { older }\end{array}$ & $\%(95 \% \mathrm{Cl})$ & & $\begin{array}{l}\text { Projected } \\
\text { number of } \\
\text { people aged } \\
50 \text { years and } \\
\text { older }\end{array}$ & $\%(95 \% \mathrm{Cl})$ \\
\hline Blindness & 16115 & 4.9 (3.9 to 6.0$)$ & 20598 & 6.9 (5.1 to 8.6$)$ & 0.046 & 36715 & 5.9 (4.8 to 6.9$)$ \\
\hline EVI & 54664 & 16.7 (14.6 to 18.8$)$ & 56792 & 18.9 (16.8 to 21.0$)$ & 0.151 & 111452 & 17.8 (16.0 to 19.5$)$ \\
\hline
\end{tabular}

*Two-sample test of proportions using the adjusted prevalence estimates for male and female subgroups.

EVI, early vision impairment; MVI, moderate vision impairment; SVI, severe vision impairment.

in the sample (table 3). Accordingly, $74.9 \%$ of causes of blindness were avoidable through either treatment or prevention. Non-trachomatous corneal opacity is not classified further by specific corneal disorders in the RAAB methodology. Onchocerciasis is not endemic in Egypt; however, a single case of onchocerciasis blindness was recorded in a man previously resident in Sudan, now living in the Sohag governorate.

$84.5 \%$ of SVI was avoidable; $62.0 \%$ was treatable $(60.5 \%$ due to cataract and $1.5 \%$ due to refractive error), while preventable causes (cataract surgical complications, glaucoma, diabetic retinopathy, trachomatous and nontrachomatous corneal opacities) together constituted $22.5 \%$
Uncorrected refractive error contributed little to the prevalence of blindness, SVI or MVI but was the main cause of EVI (53.6\%). $17.1 \%$ of the sample had refractive error, the majority of which was uncorrected (73.7\%). The estimated proportion of the sample with uncorrected presbyopia was $95.5 \%$.

\section{Cataract blindness and vision impairment}

The age-adjusted and sex-adjusted prevalence of bilateral blindness with correction due to cataract (defined as pinhole VA less than 3/60 in both eyes with obvious lens opacity in both eyes) was $1.5 \%$ (95\% CI $1.1 \%$ to $2.0 \%$ ), with no difference between men and women $(1.5 \%(95 \%$

Table 3 Causes of blindness, SVI, MVI and EVI based on participants' presenting VA

\begin{tabular}{|c|c|c|c|c|c|c|c|c|}
\hline & \multicolumn{2}{|c|}{ Blindness } & \multicolumn{2}{|c|}{ Severe VI } & \multicolumn{2}{|c|}{ Moderate VI } & \multicolumn{2}{|c|}{ Early VI } \\
\hline & $\mathrm{n}$ & $\%$ & $\mathbf{n}$ & $\%$ & n & $\%$ & $\mathbf{n}$ & $\%$ \\
\hline Refractive error & 1 & 0.4 & 3 & 1.5 & 109 & 13.6 & 394 & 53.6 \\
\hline Aphakia, uncorrected & 0 & 0 & 0 & 0 & 0 & 0 & 0 & 0 \\
\hline Cataract, untreated & 105 & 41.2 & 121 & 60.5 & 366 & 45.8 & 151 & 20.5 \\
\hline Cataract surgical complications & 20 & 7.8 & 20 & 10 & 53 & 6.6 & 23 & 3.1 \\
\hline Trachomatous corneal opacity & 2 & 0.8 & 3 & 1.5 & 11 & 1.4 & 6 & 0.8 \\
\hline Non-trachomatous corneal opacity & 40 & 15.7 & 14 & 7 & 34 & 4.3 & 11 & 1.5 \\
\hline Phthisis & 0 & 0 & 0 & 0 & 0 & 0 & 0 & 0 \\
\hline Onchocerciasis & 1 & 0.4 & 0 & 0 & 0 & 0 & 0 & 0 \\
\hline Glaucoma & 21 & 8.2 & 4 & 2 & 12 & 1.5 & 7 & 1 \\
\hline Diabetic retinopathy & 1 & 0.4 & 4 & 2 & 14 & 1.8 & 5 & 0.7 \\
\hline $\begin{array}{l}\text { Age Related Macular Degeneration } \\
\text { (ARMD) }\end{array}$ & 5 & 2 & 3 & 1.5 & 9 & 1.1 & 4 & 0.5 \\
\hline Other posterior segment disease & 37 & 14.5 & 25 & 12.5 & 183 & 22.9 & 121 & 16.5 \\
\hline $\begin{array}{l}\text { All other globe/Central Nervous } \\
\text { System } \\
\text { (CNS) abnormalities }\end{array}$ & 22 & 8.6 & 3 & 1.5 & 9 & 1.1 & 13 & 1.8 \\
\hline Total & 255 & 100 & 200 & 100 & 800 & 100 & 735 & 100 \\
\hline
\end{tabular}

EVI, early vision impairment; MVI, moderate vision impairment; SVI, severe vision impairment; VA, visual acuity. 
Table 4 Age-adjusted and sex-adjusted prevalence of bilateral cataract blindness, SVI, MVI and EVI (with best corrected VA) and the projected number of people aged 50 years and older affected in Sohag governorate

\begin{tabular}{|c|c|c|c|c|c|c|}
\hline & \multicolumn{2}{|l|}{ Men } & \multicolumn{2}{|l|}{ Women } & \multicolumn{2}{|l|}{ Total } \\
\hline & $\begin{array}{l}\text { Projected number } \\
\text { of people aged } 50 \\
\text { years and older }\end{array}$ & $\%(95 \% \mathrm{Cl})$ & $\begin{array}{l}\text { Projected number } \\
\text { of people aged } 50 \\
\text { years and older }\end{array}$ & $\%(95 \% \mathrm{Cl})$ & $\begin{array}{l}\text { Projected number } \\
\text { of people aged } 50 \\
\text { years and older }\end{array}$ & $\%(95 \% \mathrm{Cl})$ \\
\hline Blindness & 4808 & 1.5 (0.9 to 2.0$)$ & 4750 & 1.6 (0.8 to 2.4$)$ & 9558 & 1.5 (1.0 to 2.0 ) \\
\hline SVI & 3043 & 0.9 (0.5 to 1.4$)$ & 5332 & 1.8 (1.0 to 2.5$)$ & 8375 & 1.3 (0.9 to 1.8$)$ \\
\hline MVI & 15636 & 4.8 (3.6 to 5.9 ) & 17761 & 5.9 (4.6 to 7.2$)$ & 33397 & 5.3 (4.3 to 6.3 ) \\
\hline
\end{tabular}

EVI, early vision impairment; MVI, moderate vision impairment; SVI, severe vision impairment; VA, visual acuity.

CI $0.9 \%$ to $2.0 \%$ ) and $1.6 \%$ (95\% CI $0.8 \%$ to $2.4 \%$ ), respectively (table 4 ).

The age-adjusted and sex-adjusted prevalence of unilateral cataract blindness was $6.8 \%$ (95\% CI $6.1 \%$ to $7.6 \%$ ), with more women $(8.4 \%$ (95\% CI $7.1 \%$ to $9.7 \%)$ ) affected than men $(5.4 \%$ (95\% CI $4.5 \%$ to $6.3 \%))$.

\section{Effective CSC}

The CSC (in persons) for operable cataract causing $\mathrm{VA}<3 / 60$ was $86.8 \%$. The figure was similar in women $(89.2 \%)$ and men $(84.3 \%)$. CSC for $\mathrm{VA}<6 / 60$ and $<6 / 18$ were $79.3 \%$ and $61.2 \%$, respectively, with slightly higher coverage in women than men for both $(80.6 \%$ vs $77.9 \%$ and $63.0 \%$ vs $59.5 \%$, respectively). eCSC was approximately half that of the CSC for the sample and, in contrast to CSC, effective coverage was higher in men than women at all three levels of vision (table 5).

\section{Cataract surgical outcome}

$99.2 \%$ of all operated eyes were pseudophakic, with most surgeries done in private $(66.0 \%)$ or government (24.3\%) hospitals.

Considering presenting VA, visual outcome was good $(\geq 6 / 18)$ in $46.1 \%$, borderline $(<6 / 18$ to $6 / 60)$ in $25.6 \%$ and poor $(<6 / 60)$ in $28.3 \%$ of operated eyes. Poor outcomes occurred in $25.1 \%$ of eyes in men and $31.8 \%$ of eyes in women.

\begin{tabular}{|c|c|c|c|}
\hline & Men (\%) & Women (\%) & Total (\%) \\
\hline \multicolumn{4}{|l|}{ CSC } \\
\hline$V A<3 / 60$ & 83.4 & 89.2 & 86.6 \\
\hline$V A<6 / 60$ & 77.9 & 80.6 & 79.3 \\
\hline VA $<6 / 18$ & 59.5 & 63 & 61.2 \\
\hline \multicolumn{4}{|c|}{ Effective CSC } \\
\hline$V A<3 / 60$ & 51 & 39 & 44.9 \\
\hline$V A<6 / 60$ & 45.9 & 34.9 & 40.4 \\
\hline$V A<6 / 18$ & 33.9 & 26.1 & 30.2 \\
\hline
\end{tabular}

CSC, cataract surgical coverage; VA, visual acuity.
Poor patient selection (eg, presence of comorbidities) and surgical complications were the most common causes of poor $(58.0 \%$ and $32.1 \%$, respectively) and borderline (44.9\% and $30.2 \%)$ visual outcomes. With pinhole correction, the proportions of eyes with good, borderline and poor surgical outcomes were $55.4 \%, 20.9 \%$ and $23.8 \%$, respectively; $48.8 \%$ of eyes with a presenting VA of $6 / 18$ but not 6/12 would benefit from distance spectacles, based on an observed improvement with pinhole.

Visual outcome was more favourable for eyes operated in private hospitals than charitable or faith-based organisations and government sites; good outcomes were achieved in $52.5 \%$ of eyes compared with $43.8 \%$ and $30.4 \%$, respectively. Almost half of eyes operated at government hospitals $(44.1 \%)$ had poor postoperative VA $(<6 / 60)$. The proportion of eyes operated at government hospitals was similar in men and women $(26.0 \%$ and $22.3 \%$, respectively).

For all operated eyes, visual outcomes were slightly better with more recent surgery. Good outcomes were achieved in $50.1 \%$ of operations in the past 3 years, dropping to $42.7 \%$ in $4-6$ years previously and $43.9 \%$ in 7 or more years ago. Poor outcomes had reduced over the same time periods.

\section{Barriers to cataract surgery}

Among people with bilateral cataract and best-corrected $\mathrm{VA}<6 / 60$, the most frequently reported barrier to surgery was cost $(51.5 \%)$, followed by 'need not felt' $(28.7 \%)$. A slightly lower proportion of women than men reported cost as a barrier $(47.7 \%$ and $54.9 \%$, respectively).

\section{DISCUSSION}

The survey had a high response rate $(98.9 \%)$. This was achieved as the survey teams revisited participants who were eligible but unavailable at first visit. Women and younger ages (50-59) were under-represented relative to the proportions available from the census data. Consequently, we reported age-adjusted and sex-adjusted estimates where available from the standardised survey analysis. The rapid survey methodology may have underestimated the contribution of posterior segment conditions to the burden of vision impairment in the governorate. ${ }^{16}$ 
Uncorrected presbyopia may be overestimated in this study as the methodology assumes all participants require presbyopic correction. A previous study from Tanzania has suggested not all people aged 50 years and older are in fact presbyopic. ${ }^{17}$ Near spectacle use was self-reported and, as such, may be under-reported or over-reported.

The age-adjusted and sex-adjusted prevalence of blindness in the population 50 years and older in Sohag governorate was $5.9 \%$ (95\% CI $4.8 \%$ to $6.9 \%)$. This area shares many demographic and cultural characteristics with the wider Upper Egypt region; however, we cannot generalise our findings too broadly. The most recent populationbased estimate of blindness (PVA <3/60) for the same age group in Egypt was 7.9\% in 2000 in Menofiya governorate in Nile delta. Compared with this finding, the point prevalence estimate of blindness in Egypt has decreased, but is higher than estimates from recent RAAB surveys in the region. Districts in upper-middle income countries, such as Libya, Iran and Jordan, have reported blindness estimates of $2.7 \%,{ }^{18} 1.9 \%$ and $1.2 \%,{ }^{10}$ respectively. Our estimate was also higher than results from districts in other lower-middle income countries in the EMR region, for example, Sudan $(4.9 \%)$ and Pakistan $(4.2 \%) .{ }^{20}$ Only surveys in Sennar state, Sudan (2010) and Lahij and Amran governorates in Yemen (2009) found higher prevalence of blindness of $7.4 \%$, $10.8 \%$ and $9.3 \%$, respectively. ${ }^{20} 21$

Cataract was the most common cause of blindness (41.2\%), SVI (60.7\%) and MVI $(45.8 \%)$ overall, and in both men and women separately. This is in keeping with the survey in Menofiya in 2000 which also reported cataract as the main cause of 'blindness' (defined as VA $<6 / 60$, equivalent to SVI here) at $64 \%$. CSC at that time was reported to be only $13 \%$, although, at which level of vision impairment was not reported.

In Sohag, there are approximately 16 ophthalmologists per million people ${ }^{5}$ slightly lower than the WHO target for EMR of $20 .^{22}$ At the national level, ophthalmologist density was estimated to be 65.6 per million in 2015; however, only one third (24.6 per million) of these perform cataract surgery. ${ }^{22}$

The density of ophthalmologists in Egypt is higher than the neighbouring countries with lower prevalence of blindness. For example, Libya, Jordan and Iran had 41.4, 44.8 and 21.5 ophthalmologists per million populations, respectively. ${ }^{23}$ Although ophthalmologist density may not necessarily be a strong predictor of blindness in a region, ${ }^{23}$ advancing the surgical capacity of the ophthalmic human resources available in Egypt should be a priority in efforts to reduce avoidable blindness. The distribution of cataract surgeons relative to population need should be reviewed and strategies to redress imbalances may need to be considered.

The poor quality of cataract surgeries performed was an important contributor to the relatively high prevalence of blindness. Despite CSC for VA $<3 / 60$ reaching $90 \%$, when eCSC (a measure of coverage and surgical quality) was considered, this dropped to $45 \%$, and almost a quarter of cataract surgeries resulted in poor visual outcome, much higher than the WHO target of less than $5 \% .{ }^{24}$ A review of cataract surgical training programmes and skills of trainees may be indicated to identify gaps in training contributing to poor surgical outcomes.

The higher prevalence of SVI and MVI among women compared with men was found to be statistically significant. There was only borderline statistical significance for the difference between the higher female blindness estimate compared with the male blindness estimate; however, this trend is consistent with previous studies in other governorates in Egypt. ${ }^{11}{ }^{12}$ Gender inequity in vision impairment has often been reported to be a consequence of lower utilisation of eye care services by women than men. ${ }^{25}$ Gender-specific barriers in this governorate may include the financial burden of seeking eye care, as Sohag has the highest rate of women who are the only source of income for their families $(23.5 \%) .{ }^{26}$ Moreover, $53 \%$ of women in Sohag were not subscribed to, or beneficiaries of, health insurance compared with $47 \%$ for men in $2017 . .^{5}$

In this survey, cost and 'need not felt' were the most frequently reported barriers to surgery, similar to previous findings from LMIC. ${ }^{27} \mathrm{CSC}$ was similar in women and men, suggesting that access to cataract surgical services was not affected by sex. However, when eCSC was considered, the coverage of quality cataract services was higher in men than women. Good outcomes were more likely at private hospitals than government facilities; however, the proportion of eyes operated at each were similar in men and women. Women appears to suffer a cataract surgical quality deficit, but the reason for that is not clear from these data.

Although cataract surgery is provided at no or low cost at teaching and government hospitals, users tend to make out of pocket payments for private sector surgeries, even those who have insurance. ${ }^{28}$ Anecdotally, surgery at government hospitals may cost up to $\$ 50$, while the cost of private surgery ranges from $\$ 250$ to $\$ 500$. The type of surgery and associated outcomes are an important influence on service utilisation. Phacoemulsification is typically offered at private facilities, unlike at government hospitals where ECCE is normally performed. ${ }^{6}$ A 2014 study reported that, within the public sector, ophthalmologists felt there were a lack of training, supervision and incentives, while managers were concerned with a lack of government financial and technical support. ${ }^{6}$

While more cataract surgeries are needed to address the high prevalence of blindness, improving the proportion of good visual outcomes should occur in parallel. This may require investment in facilities and well-structured training programmes for government ophthalmologists. At the same time, as the private sector is a major service provider, partnerships and innovations in health financing can mitigate out of pocket expenditure on cataract surgery. Both government and private clinics will require ongoing monitoring of cataract surgical outcomes. ${ }^{29}$

Non-trachomatous corneal opacity was the second most common cause of blindness, followed by the other posterior segment diseases and other globe or central nervous system diseases categories. Further information on the 
causes of non-trachomatous corneal opacity are not available from this survey but merit further investigation as public health interventions for avoidable causes may be feasible. We found no other relevant literature on the causes of non-trachomatous corneal opacity in the population in Egypt.

Only $17 \%$ of participants in the survey sample had refractive errors; however, $75 \%$ were uncorrected. As the main cause of mild VI, and considering the likely high burden of near vision impairment, further understanding of barriers to spectacle wear is warranted.

\section{CONCLUSION}

The prevalence of blindness in Sohag governorate in Egypt is higher than districts in other middle-income countries in the region. Most of the causes of blindness and vision impairment are avoidable. The gender gap in eye health remains a key issue to be considered by policy makers. Improvements in the quality of cataract surgery are required. Alongside further population-based studies of the prevalence and causes of blindness in Egypt, eye health system assessments should precede planning to better align services with the population need. Building on the capacities of government facilities is critical to increase the utilisation of services and provide quality, equitable eye care. Partnerships with private sector and civil society organisations can be an efficient tool to improve the affordability of the services.

Acknowledgements We would like to extend our gratitude to Dr Khaled Amer, the national eye health coordinator at the Ministry of Health and Population. Not to forget the efforts by Dr Ahmed EIMansour and Mr Adel Fawzy from Magrabi team. We also appreciate the acceptance and participation of the study population.

Contributors HA, MS and GE conceived and planned the presented study. CDM (a certified rapid assessment of avoidable blindness trainer) oversaw delivery of the survey methodology and training of fieldwork teams. HA was responsible for data acquisition and handling. IM and $\mathrm{HA}$ reviewed the survey findings and wrote the manuscript with input from all authors.

Funding This study was made possible thanks to the generous fund of Canada Fund for Local Initiatives (CFLI).

Competing interests None declared.

Patient consent for publication Not required.

Ethics approval Ethical approval for the study was obtained from the Egyptian Ministry of Health and Population. The field teams explained the purpose of the study and gained consent prior to data collection (see online supplemental file 1). Participants identified with eye conditions were counselled and referred for further care.

Provenance and peer review Not commissioned; externally peer reviewed.

Data availability statement Data are available in a public, open access repository. The data of the study will be available through the RAAB repository at http://raabdata.info/repository/. Unless otherwise stated, content on this website is licensed for re-distribution under the Creative Commons AttributionNonCommercial-ShareAlike 4.0 International License.

Open access This is an open access article distributed in accordance with the Creative Commons Attribution Non Commercial (CC BY-NC 4.0) license, which permits others to distribute, remix, adapt, build upon this work non-commercially, and license their derivative works on different terms, provided the original work is properly cited, appropriate credit is given, any changes made indicated, and the use is non-commercial. See: http://creativecommons.org/licenses/by-nc/4.0/.

\section{ORCID iD}

Heba AlSawahli http://orcid.org/0000-0002-2922-8354

\section{REFERENCES}

1 Regional office for Eastern Mediterranean Region W. Control and prevention of blindness and deafness 2019. Available: http://www. emro.who.int/control-and-preventions-of-blindness-and-deafness/ about-the-programme/about-the-programme.html

2 Central Agency for Public Mobilization and Statistics. Governorates population 2019. Available: https://www.capmas.gov.eg/Pages/ populationClock.aspx

3 The World Bank. GDP per capita 2018. Available: https://data. worldbank.org/indicator/ny.gdp.pcap.cd

4 World Bank. World Bank group to extend current strategy in Egypt to maintain momentum on reforms [press release], 2019.

5 Central Agency for Public Mobilization and Statistics. Results of Egypt census 2017. Available: https://www.capmas.gov.eg/party/ party.html

6 Elbieh I, Bascaran C, Blanchet K, et al. Trends in cataract surgical rate and resource utilisation in Egypt. Ophthalmic Epidemiol 2018;25:351-7.

7 Said ME, Goldstein H, Korra A, et al. Prevalence and causes of blindness in urban and rural areas of Egypt. Public Health Rep 1970;85:587-99.

8 Ezz al Arab G, Tawfik N, El Gendy R, et al. The burden of trachoma in the rural Nile delta of Egypt: a survey of Menofiya governorate. $\mathrm{Br} \mathrm{J}$ Ophthalmol 2001;85:1406-10.

9 Fouad D, Mousa A, Courtright P. Sociodemographic characteristics associated with blindness in a Nile delta governorate of Egypt. $\mathrm{Br} \mathrm{J}$ Ophthalmol 2004;88:614-8.

10 IAPB Vision Atlas. Global vision database maps 2017. Available: http://atlas.iapb.org/gvd-maps/\#AllAges

11 Courtright P, Sheppard J, Schachter J, et al. Trachoma and blindness in the Nile delta: current patterns and projections for the future in the rural Egyptian population. Br J Ophthalmol 1989;73:536-40.

12 Mousa A, Courtright P, Kazanjian A, et al. Prevalence of visual impairment and blindness in upper Egypt: a gender-based perspective. Ophthalmic Epidemiol 2014;21:190-6.

13 Kuper H, Polack S, Limburg H. Rapid assessment of avoidable blindness. Community Eye Health 2006;19:68-9.

14 Majeed A, El-Sayed AA, Khoja T, et al. Diabetes in the MiddleEast and North Africa: an update. Diabetes Res Clin Pract 2014;103:218-22.

15 Ramke J, Gilbert CE, Lee AC, et al. Effective cataract surgical coverage: an indicator for measuring quality-of-care in the context of universal health coverage. PLoS One 2017;12:e0172342.

16 Zhang XJ, Leung CKS, Li EY, et al. Diagnostic accuracy of rapid assessment of avoidable blindness: a population-based assessment. Am J Ophthalmol 2020;213:235-43.

17 Burke AG, Patel I, Munoz B, et al. Population-based study of presbyopia in rural Tanzania. Ophthalmology 2006;113:723-7.

18 Rabiu MM, Jenf M, Fituri S, et al. Prevalence and causes of visual impairment and blindness, cataract surgical coverage and outcomes of cataract surgery in Libya. Ophthalmic Epidemiol 2013;20:26-32.

19 Katibeh M, Behboudi H, Moradian S, et al. Rapid assessment of avoidable blindness and diabetic retinopathy in Gilan Province, Iran. Ophthalmic Epidemiol 2017;24:381-7.

20 RAAB repository. Repository data 2014-2016. Available: http:// raabdata.info/repository/

21 Al-Khatib T, Hameed A, Ahmed A. Rapid assessment of avoidable blindness in amran and lahj governorates of Yemen. Sudanese $J$ Ophthalmol 2013;5:9-16.

22 Regional office for Eastern Mediterranean Region W. Implementation of vision 2020 in the eastern Mediterranean region, 2003.

23 Resnikoff S, Lansingh VC, Washburn L, et al. Estimated number of ophthalmologists worldwide (international Council of ophthalmology update): will we meet the needs? Br J Ophthalmol 2020;104:588-92.

24 Pararajasegaram R. Importance of monitoring cataract surgical outcomes. Community Eye Health 2002;15:49-50.

25 Lewallen S, Courtright P. Gender and use of cataract surgical services in developing countries. Bull World Health Organ 2002;80:300-3.

26 Central Agency for Public Mobilization and Statistics. Women and men in Egypt, 2015, 2017.

27 Lewallen S, Mousa A, Bassett K, et al. Cataract surgical coverage remains lower in women. Br J Ophthalmol 2009;93:295-8.

28 Nakhimovsky S, Glandon D, Rafeh N, et al. Egypt National health accounts: 2008/09, 2011.

29 Limburg H, Foster A, Gilbert C, et al. Routine monitoring of visual outcome of cataract surgery. Part 1: development of an instrument. Br J Ophthalmol 2005;89:45-9. 